\title{
Serum Prolactin Level and Diabetic Retinopathy in Type 2 Diabetes
}

\section{Bonakdaran Shokoofeh ${ }^{1}$, Shoeibi Nasser ${ }^{2}$, Mojtaba Abrishami ${ }^{2}$ and Rokni Haleh ${ }^{1 *}$}

${ }^{1}$ Endocine Research Center, Mashad University of Medical Sciences, Iran

${ }^{2}$ Eye disease research center, Mashad University of Medical Sciences, Iran

\begin{abstract}
Retinopathy is a common complication of type 2 diabetes. Several factors including hyperglycemia and hypertension play important roles in retinopathy progression. However, the actual mechanistic pathways are not yet discovered. Prolactin via its antiangiogenic characteristics may exert protective effects on retina. We performed a case- control study in order to investigate the potential role of 23KD prolactin in retinopathy.
\end{abstract}

A total of 212 type 2 diabetics were recruited in this study. According to retinopathy they were divided into two groups. Group one (70 patients) suffered diabetic retinopathy and group two (142 patients) did not have retinopathy. There were significant differences in diabetes duration and hyperglycemia and systolic hypertension between two groups $(p<0.05)$. However we did not find any significant difference in prolactin level between two groups $(p>0.05)$. Serum $23 \mathrm{KD}$ prolactin does not seem to have protective role in diabetes retinopathy.

Keywords: Retinopathy; Prolactin; Diabetes; Anti-angiogenesis

\section{Introduction}

Retinopathy is a common microvascular complication of diabetes mellitus. It is the most common cause of blindness during reproductive years. Nearly all patients with diabetes will have some degree of retinopathy within 20 years of their diagnosis [1]. Although there is no clear etiologic factor for this complication, multiple conditions including hyperglycemia, duration since diabetes diagnosis, hypertension, inflammatory factors and even age at the time of diagnosis play crucial role in its pathogenesis [2]. The increased understanding of the mechanistic pathways causing hyperglycemia-induced retinopathy has precisely emerged new targets against which novel therapies have been innovated. Diabetic retinopathy is characterized by capillary cell reduction and increased vasopermeability which induce hypoxia and ischemia concluding to increased angiogenesis [3]. Disturbance in antiangiogenic protection mechanisms can accelerate neovascularization and retinopathy. Vasoinhibins are peptides derived from prolactin (PRL), growth hormone and placenta lactogen. Cathepsin-D or matrix metaloproteases proteolytically cleave PRL to $16 \mathrm{KD} \mathrm{N}$-terminal fragments with antiangiogenic actions [4]. Theses peptides decrease vasodilatation and angiogenesis [5]. Animal studies have demonstrated that Vasoinhibins antagonize vascular endothelial growth factor (VEGF) and reduce NOS activation [6]. PRL, which is secreted from pituitary gland provides other benefits when produced locally in multiple human tissue such as endothelial cells [7]. PRL is expressed throughout retina [4]. One animal study proved that intracardiac radioactive PRL injection will incorporate into ocular tissue [8]. A study reported that PRL level is increased in diabetics and it is lower in patients with retinopathy than in diabetics without retinopathy [9]. The authors of this study claimed that inducing hyperprolactinemia may represent a novel therapy against diabetic retinopathy [9]. We performed a case-control study in order to investigate the probable role of $23 \mathrm{KD}$ prolactin (PRL), as a source of intraocular Prolactin [9], in diabetic retinopathy.

\section{Material and Methods}

\section{Outcome measures}

A total of 212 patients with type 2 diabetes, evaluated for inclusion/ exclusion criteria and enrolled in the study. Inclusion criteria included type 2 diabetes according to ADA diagnostic criteria [10]. Exclusion criteria were drugs and medical conditions that affect serum prolactin level consisting of: medical history of prolactinoma, hypothyroidism, chronic renal failure, liver cirrhosis and treatment with drugs that increase prolactin level, pregnancy and breast feeding, recent psychologic stress, recent hospitalization, acromegaly and cushing disease. Age, diabetes duration ( $<5$ years, $5-10$ years, $>10$ years ), diabetes treatment (insulin, oral agents), body weight and blood pressure were recorded in a data collection sheet. Retina specialist carried out complete ophthalmic exam including indirect ophthalmoscopy and fundus exam with contact lens. In each patient, the eye with worse level of retinopathy was considered as the level of retinopathy in that patient. According to the presence or absence of abnormal new blood vessels emanating from the retina, diabetic retinopathy divides into Nonproliferative or proliferative. Non- proliferative diabetic retinopathy (NPDR) can be further classified according to severity (Table 1) [11]. Blood samples drawn from cubital vein between 8 and 10 am after at least 8 hours fasting ,before medication administration and checked for fasting blood sugar(FBS), hemoglobin $\mathrm{A} 1 \mathrm{C}(\mathrm{HbA1C})$, serum lipid profile, creatinin and prolactin level.Insulin level was measured only in patients who did not recieive insulin. Albumin to creatinin ratio in spot urine sample was also checked for all patients. Values of albumin/ creatinin between $30-300 \mathrm{mg} / \mathrm{gr}$ and over $300 \mathrm{mg} / \mathrm{gr}$ in spot urine were considered as microalbuminuria or macroalbuminuria respectively [12]. Blood pressure more than $130 / 80$ is defined as hypertension in diabetics [13]. FBS was measured by glucose oxidize method (Human,

*Corresponding author: Rokni Haleh, Endocrine Research Center, Mashad University of Medical Sciences, Iran, Tel: 00985118012976; Fax: 00985118406757; E-mail: roknih@mums.ac.ir

Received October 16, 2011; Accepted Feberuary 15, 2012; Published Feberuary 20, 2012

Citation: Shokoofeh B, Nasser S, Abrishami M, Haleh R (2012) Serum Prolactin Level and Diabetic Retinopathy in Type 2 Diabetes. J Diabetes Metab 3:173. doi:10.4172/2155-6156.1000173

Copyright: () 2012 Shokoofeh B, et al. This is an open-access article distributed under the terms of the Creative Commons Attribution License, which permits unrestricted use, distribution, and reproduction in any medium, provided the original author and source are credited. 


\section{Mild NPDR}

At least one microaneurism

Criteria not met for other level of retinopathy

Moderate NPDR

Hemorrhage/microaneurism>= standard photograph

Soft exudates(cotton wool spots),Venus beading and intraretinal microvascuar abnormality definitely present

Criteria not met for sever NPDR or very sever NPDR or PDR

Sever NPDR

Hemorrhage/microaneurism>= standard photograph in all 4 quadrants

Or Venus beading in at least two quadrants

Or Intraretinal microvascular abnormality $>=$ standard photograph in at least one quadrant

Table 1: Classification of non-proliferative diabetic retinopathy according to the severity.

Germany) and HbAlc by chromatography (Biosource Kit, Barcelona Spain), lipids were measured by enzymatic methods (Parsazmon Karaj, Iran) and insulin by IRMA (Immunothec, Beckman) kits and prolactin by (Immunotech, Beckman Intraassay2.8\%) kits. Homeostasis model assessment-insulin resistance (HOMA-IR) index was calculated to measure insulin resistance in patients who did not receive insulin.

$$
\text { HOMA }-\mathrm{IR}=\frac{\text { insulin } \mathrm{X} \text { blood sugar }(\mathrm{mmol} / \mathrm{lit})}{22.5}
$$

Institutional Review Board and Ethics Committee of Mashhad University of Medical Sciences approved the study and all participants filled the informed consent.

Statistical analysis was performed using SPSS software, Statistical Package for Social Sciences, version 11.5 SPSS, Inc. Chicago, IL, USA. Qultitative variables were expressed as percentages, and quantitative data were described as mean values with standard deviations (SD) and /or confidence interval (CI). The student t-test, $\mathrm{Z}$ test, analysis of variance (ANOVA) and Mann-Whitney test were used as indicated for inferential statistics. Normal distributions of quantitative data were assessed using the Kolmogrov-Smirnov test. P-values less than 0.05 assumed to be statistically significant.

\section{Results}

We enrolled 212 type two diabetics to the study. The case group consisted of 70 patients with type 2 diabetes mellitus who suffered either proliferative $(n=24)$ or non-proliferative $(n=46)$ diabetic retinopathy. The control group consisted of 142 type 2 diabetics without retinopathy. The control group had a mean age of $54.1 \pm 10$ years while the mean age of case group was $58.6 \pm 7$ years which was significantly different $(\mathrm{P}=0.04)$. (Table 2 ) illustrates other demographic characteristics. Duration of diabetes since diagnosis was significantly higher in retinopathy group $(\mathrm{p} \leq 0.001)$. Coronary vascular disorder was positive in $33.8 \%$ of retinopatic and $24.1 \%$ of none retinopathic patients $(\mathrm{P}=0.1)$. Among case group $13.5 \%$ had nephropathy while $5 \%$ of control group showed nephropathy $(\mathrm{p}=0.03)$. Hypertension was present in $52.2 \%$ of control and $66.2 \%$ of case group $(\mathrm{p}=0.06)$.Duration of diabetes since diagnosis was significantly higher in patients suffered retinopathy than those without retinopathy $(\mathrm{P} \leq 0.001)$. HbA1C was also significantly higher in case group $(\mathrm{P}<0.001)$.

Statistical analysis revealed that $23 \mathrm{KD}$ PRL serum concentration was not different in two groups. The case group had a concentration of $6.29 \pm 3.19 \mathrm{ng} / \mathrm{ml}$ and the control group had a concentration of 6.44 $\pm 3.88 \mathrm{ng} / \mathrm{ml}$ and the difference was not statistically significant $(\mathrm{P}=0.94)$.
Patients with nonprolifrative retinopathy were divided into 3 groups according to the severity of their retinal disorder. Their characteristics is shown in (Table 3). There was no significant difference between these groups according to the level of $23 \mathrm{KD}$ PRL ( $\mathrm{p}=0.73$ ).

\section{Discussion and Conclusion}

A total of 212 patients with type 2 diabetes mellitus were enrolled in this study. There was no difference in serum $23 \mathrm{KD}$ PRL level between retinopathic and non-retinopathic diabetics. The association between PRL and diabetic retinopathy has been always a matter of controversy. Considerable number of studies performed on this issue and they demonstrated increased [14], decreased [15], or normal [16] PRL concentration in patients with diabetic retinopathy. PRL is the main source of vasoinhibins [4]. Study of vasoinhibins in animal models demonstrated that these proteins, derived from prolactin hormon, could decrease vasopermeability and antagonize the proangiogenic effects of VEGF [6]. Arnold et al. also reported that all diabetics had higher level of circulating prolactin than the control subjects and those without retinopathy had higher concentration compared with patients with proliferative retinopathy [9]. Triebel et al. developed a new technique to measure prolactin- $\mathrm{V}$ (vasoinhibin) levels in the sera of retinopathic diabetics and compared it with a group of normal males. They concluded that diabetic patients had lower level of this protein [17]. Mooradian and colleagues performed a case-control study and showed that prolactin level although in most cases stayed in normal range, was significantly higher in diabetics compared to normal group. However, they did not find any association between serum PRL level and $\mathrm{HbA1C}$, insulin concentration or retinopathy [14]. Present study evaluated diabetics with or without retinopathy and in contrary to Mooradian and Arnold study; we did not measure prolactin level in normal participants. However, in our study, we performed subgroup analysis according to the level of retinopathy and although those who had sever non-proliferative retinopathy had lower PRL concentration, the difference was not statistically significant. However, the lower number of patients in the case group may explain this.

\begin{tabular}{|llll|}
\hline Characteristic & $\begin{array}{c}\text { case group } \\
(\mathbf{n}=\mathbf{7 0})\end{array}$ & $\begin{array}{c}\text { Control group } \\
(\mathbf{n = 1 4 2 )}\end{array}$ & P value \\
\hline Male & $\mathrm{n}=21(28 \%)$ & $\mathrm{n}=44(33 \%)$ & 0.64 \\
BMI $\left(\mathrm{kg} / \mathrm{m}^{2}\right)$ & $27.74 \pm 5.15$ & $28.22 \pm 5.55$ & 0.78 \\
sysBP $(\mathrm{mmHg})$ & $129.7 \pm 2.25$ & $122.8 \pm 1.18$ & 0.007 \\
diaBP $(\mathrm{mmHg})$ & $78.09 \pm 1.19$ & $76.32 \pm 1.18$ & 0.31 \\
Duration $>10$ years & $\mathrm{n}=50(66.7 \%)$ & $\mathrm{n}=45(32.1 \%)$ & 0.00 \\
Insulin therapy & $\mathrm{n}=35(46.7 \%)$ & $\mathrm{n}=19(13.4 \%)$ & 0.00 \\
FBS $(\mathrm{mg} / \mathrm{dl})$ & $187.28 \pm 84.24$ & $163.3 \pm 59.14$ & 0.08 \\
HbA1C $(\%)$ & $9.40 \pm 1.72$ & $8.40 \pm 1.87$ & 0.00 \\
Cholesterol $(\mathrm{mg} / \mathrm{dl})$ & $176.32 \pm 41.79$ & $174.79 \pm 39.28$ & 0.79 \\
LDL $(\mathrm{mg} / \mathrm{dl})$ & $104.43 \pm 3.17$ & $101.53 \pm 2.93$ & 0.61 \\
HDL $(\mathrm{mg} / \mathrm{dl})$ & $42.20 \pm 8.53$ & $41.81 \pm 6.25$ & 0.61 \\
Triglyceride $(\mathrm{mg} / \mathrm{dl})$ & $161.47 \pm 10.17$ & $171.72 \pm 12.48$ & 0.56 \\
Insulin $(\mu \mathrm{uu} / \mathrm{L})$ & $11.50 \pm 9.7$ & $11.01 \pm 5.20$ & 0.26 \\
Homa IR & $1.82 \pm 1.40$ & $1.62 \pm 0.76$ & 0.00 \\
Prolactin $(\mathrm{ng} / \mathrm{ml})$ & $6.29 \pm 3.19$ & $6.44 \pm 3.88$ & 0.9 \\
\hline
\end{tabular}

BMI: Body Mass Index; sysBP: Systholic Blood Pressure; diaBP: Diastholic Blood Pressure; Duration: years since diagnosis of DM

Table 2: Demographic and laboratory characteristics of the study population.

\begin{tabular}{|l|l|l|l|l|}
\hline variable & Mild & moderatre & severe & $\mathrm{P}$ \\
\hline Age & $55.3 \pm 5.9$ & $56.1 \pm 9.9$ & $58.9 \pm 7$ & 0.3 \\
Duration>10 & $47 \%$ & $70 \%$ & $84.6 \%$ & 0.1 \\
HbA1C & $8.85 \pm 1.5$ & $9.3 \pm 1.1$ & $9.7 \pm 2$ & 0.3 \\
HOMA-IR & $1.41 \pm 0.47$ & $1.6 \pm 0.9$ & $0.85 \pm 0.5$ & 0.1 \\
PRL $(\mathrm{ng} / \mathrm{ml})$ & $6.11 \pm 2.8$ & $6.5 \pm 3.8$ & $5.52 \pm 3.2$ & 0.5 \\
\hline
\end{tabular}

Table 3: Comparisons beween NPDR groups. 
In our study, like many previous ones [18], there was significant difference in diabetes duration between retinopathic and control group and duration since diabetes diagnosis was more than 10 years in most subjects with retinopathy ( $66.7 \%$ versus $32.1 \%, \mathrm{P}=0.00)$. The time interval since the patient is exposed to abnoramally high blood sugar is an important risk factor for this complication. In few studies, however, diabetes duration independent of blood glucose level was the main factor responsible for retinopathy [19]. In this study we found a strong correlation between hyperglycemia and retinopathy and glycosylated hemoglubolin ( $\mathrm{HbAlC}$ ) was significantly higher in case group $(\mathrm{P}=0.00)$, which resembles the UKPDS results [20]. Considerable number of studies have evaluated the impact of long term hyperglycemia on microvascular complications. In contrary to older studies recently scientists have suggested that tight blood glucose control can increase mortality [21]. The ADVANCE study even proved that retinopathy prevalence was the same in both tight and wellcontrolled group [22]. We also found significant association between retinopathy and systolic hypertension $(\mathrm{P}=0.007)$. Again, this was the same as UKPDS results. The WESDR study also proved that systolic hypertension is an important predictor of retinopathy progression in type 2 diabetics but not in type one diabetics [23]. Although most previous studies demonstrated significant association between retinopathy and hypercholesterolemia, we could not prove that high cholesterol level is a predictor of retinopathy.

One of our limitations in this study was that we could not measure the $16 \mathrm{KD}$ fragment of PRL, which proved to induce the antiangiogenic effects. Second limitation of this study was the lack of healthy control group. Sample size especially in retinopathics, can also be regarded as a limitation in this study. Designing another study that compares vasoinhibin and prolactin levels in both diabetic and healthy participants with enough sample size seems to be logical.

\section{Acknowledgement} Sciences.

This study was supported by a grant from Mashad University of Medical

\section{References}

1. Frank RN (1986) Diabetic retinopathy: current concepts of evaluation and treatment. Clin Endocrinol Metab 15: 933-969.

2. Klein R, Klein BE, Moss SE, Davis MD, DeMets DL, et al. (1988) Glycosylated hemoglobin predicts the incidence and progression of diabetic retinopathy. JAMA 260: 2864-2871.

3. Triebel J, Macotela Y, Martinez de la Escalera G, Clapp C (2011) Prolactin and Vasoinhibins: Endogenous Players in Diabetic Retinopathy. lubmb Life 63: 806-810.

4. Clapp C, Thebault S, Arnold E, Garcia C, Rivera JC, et al. (2008) Vasoinhibins: novel inhibitors of ocular angiogenesis. Am J Physiol Endocrinol Metab 295: E772-E778.

5. Clapp C, Aranda J, Gonzalez C, Jeziorski MC, de la Escalera GM, et al. (2006) Vasoinhibins: endogenous regulators of angiogenesis and vascular function. Trends Endocrinol Metab 17: 301-317

6. Garcia C, Aranda J, Arnold E, Thebault S, Macotela Y, et al. (2008) Vasoinhibins prevent retinal vasopermeability associated with diabetic retinopathy in rats via protein phosphatase 2A-dependent eNOS inactivation. J Clin Invest 118: 2291300

7. Clapp C, Lopez-Gomez FJ, Nava G, Corbacho A, Torner L, et al. (1998) Expression of prolactin mRNA and of prolactin-like proteins in endothelial cells: evidence for autocrine effects. J Endocrinol 158: 137-144.

8. O'Steen WK, Sundberg DK ( 1982) Patterns of radioactivity in the eyes of rats after injection of iodinated prolactin. Ophthalmic Res 14: 54-62.
9. Arnold E, Rivera JC, Thebault S, Moreno-Paramo D, Quiroz-Mercado H, et al. ( 2010) High Levels Of Serum Prolactin Protect Against Diabetic Retinopathy By Increasing Ocular Vasoinhibins. Diabetes 59: 3192-3197.

10. Gabir MM, Hanson RL, Dabelea D, Imperatore G, Roumain J, et al. (2000) The 1997 American Diabetes Association and 1999 World Health Organization criteria for hyperglycemia in the diagnosis and prediction of diabetes. Diabetes Care 23: 1108-1112.

11. Aiello LM (2003) Perspectives on diabetic retinopathy. Am J Ophthalmol 136 122-135.

12. KDOQI Clinical Practice Guidelines and Clinical Practice Recommendations for Diabetes and Chronic Kidney Disease. (2007) Am J Kidney Dis 49: S12-S154

13. Executive summary: Standards of medical care in diabetes--2010. (2010) Diabetes Care 33: S4-S10.

14. Mooradian AD, Morley JE, Billington CJ, Slag MF, Elson MK, et al. (1985) Hyperprolactinaemia in male diabetics. Postgrad Med J 61: 11-24.

15. Harter M, Balarac N, Pourcher P, Koslowski JM, Krebs B, et al. (1976) Diabetic retinopathy and prolactin. Lancet 2: 961-962.

16. Cerasola GA, Donatelli M, Sinagra D, Russo V, Amico LM, et al. (1981) Study of pituitary secretion in relation to retinopathy in patients with juvenile diabetes mellitus. Acta Diabetol Lat 18: 319-328.

17. Triebel J, Huefner M, Ramadori G (2009) Investigation of prolactin-related vasoinhibin in sera from patients with diabetic retinopathy. Eur $\mathrm{J}$ Endocrinol 161: $345-353$

18. Hamman R, Mayer E, Moo-Young G, Hildebrandt W, Marshall J, et al. (1989) Prevalence and risk factors of diabetic retinopathy in non-Hispanic whites and Hispanics with NIDDM. San Luis Valley Diabetes Study. Diabetes 38: 12311237.

19. Davis MD, Fisher MR, Gangnon RE, Barton F, Aiello LM, et al. (1998) Risk factors for high-risk proliferative diabetic retinopathy and severe visual loss: Early Treatment Diabetic Retinopathy Study Report\# 18. Invest Ophthalmo Vis Sci 39: 233-252.

20. Stratton IM, Adler AI, Neil HA, Matthews DR, Manley SE, et al. (2000) Association of glycaemia with macrovascular and microvascular complications of type 2 diabetes (UKPDS 35): prospective observational study. BMJ 321 405-412.

21. Dluhy RG, McMahon GT (2008) Intensive glycemic control in the ACCORD and ADVANCE trials. N Engl J Med 358: 2630-2633.

22. Chalmers J, Perkovic V, Joshi R, Patel A (2006) ADVANCE: breaking new ground in type 2 diabetes. J Hypertens Suppl 24: S22-S28.

23. Klein R, Klein BE, Moss SE (1989) The Wisconsin epidemiological study of diabetic retinopathy: a review. Diabetes Metab Rev 5: 559-570. 